\title{
Repositioning of Eugenol in Treatment of Gastric Ulcers Through Development of Floating In situ Gel
}

\author{
Arati Ranade*, Pallavi Birajdar, Prajakta Punde \\ Department of Pharmaceutics, Sinhgad College of Pharmacy, Vadgaon (Bk.), Sinhgad Road, Pune, Maharashtra, INDIA.
}

\begin{abstract}
Theoral liquid dosage forms are more prone to low bioavailability because of their quick transit from the stomach. Producing sustained release formulation of an oral liquid dosage formcould be successfully augmented through a strategy of liquid in-situ gelling system. In-situ forming polymeric formulation is in sol form before administration in the body, but once administered undergoes in-situ gelation. The objective of this study was to develop a novel in-situ gel system of eugenol for treatment of peptic ulcer. Protective effect of eugenol against ulcer is documented but less practiced. The delivery system consists of varying concentrations of sodium alginate, gellan gum and calcium carbonate. The system was subjected to various in vitro and in vivo characterizations. In vitro release studies were conducted in $0.1 \mathrm{~N} \mathrm{HCl}$ containing $5 \%$ of sodium lauryl sulphate. The finalised formulation (F16) contained gellan gum $(0.5 \% \mathrm{w} / \mathrm{v})$, calcium carbonate $(1 \%$ $\mathrm{w} / \mathrm{v})$, sodium citrate $(0.25 \% \mathrm{w} / \mathrm{v})$ and mannitol $(0.16 \% \mathrm{w} / \mathrm{v})$. It showed drug release of $97.26 \%$. The floating lag time was found to be less than 1 minute and system was found to be floating throughout the drug release time of $12 \mathrm{~h}$. The gelation occurred immediately after addition in acidic medium. The pharmacodynamics studies on F16 exhibited gastro protective activity. The standard drug omeprazole showed $62.23 \pm$ $0.63 \%$ inhibition of ulceration while formulation F16 showed $70.06 \pm 0.81 \%$ inhibition of ulceration. The in vivo X-Ray studies revels that formulation shows formation of gel in acidic environment of stomach along with floating of gel.
\end{abstract}

Key words: Floating in situ gel, Eugenol, Gellan gum, Sodium alginate, Pharmacodynamics studies, X-ray.

\section{INTRODUCTION}

Peptic ulcers are the areas of degeneration and necrosis of the mucosa of stomach or duodenum. The ulcer which is located in stomach is known as gastric ulcer. The gastric ulcer is a common global problem today. The normal stomach mucosa maintains balance between the protective and aggressive factor, when this balance is lost the gastric lesion in the stomach is developed. ${ }^{1}$ The protective factors are the bicarbonate, gastric mucus, blood flow, mucin secretion, prostaglandins synthesis and aggressive factors are like acid, pepsin secretion, Helicobacter pylori (H. pylori), bile salts, ethanol, lipid peroxidation, and nitric oxide. ${ }^{2}$ The ideal therapy to treat peptic ulcer disease is to relieve pain, heal the ulcer and delay ulcer recurrence. ${ }^{3}$ The current treatment of ulcer is combination of antibiotics and proton pump inhibitors i.e. triple therapy and histamine $\mathrm{H}_{2}$-receptor blocker. But these drugs show many adverse effects like antibiotic resistance, allergic reactions, loss of taste, depression, patient noncompliance. Thus there is need to develop alternative treatment.

The use of herbals drugs for peptic diseases is the good alternative. Eugenol shows its gastro protective activity by a various mechanism as it inhibits the platelet activating factor (PAF), decreases nitric oxide level and inhibit lipid peroxidation. ${ }^{4}$
Submission Date : 14-08-2015 Revision Date : :29-02-2016 Accepted Date : :21-03-2016

DOI: 10.5530/ijper.50.3.35 Correspondence: Arati Ranade,

Department of Pharmaceutics, Sinhgad College of Pharmacy, Vadgaon (Bk), Pune, Maharashtra-411041

Mob. No.: +918552021211 E-mail: aratiranade81@gmail. com

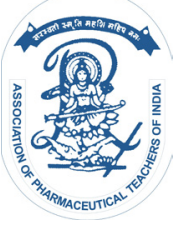

www.ijper.org 
It also shows its antiulcer activity by opening potassium channel $\left(\mathrm{K}_{\text {АTP }}\right)$ and by scavenging free radicals. ${ }^{5}$ Thus it inhibits aggressive factors (acid -pepsin secretion, lipid peroxidation, $\mathrm{NO}$ level) and increases defensive factors (mucin secretion, blood flow, gastric mucosa, prostaglandin synthesis) level in gastric mucosa. ${ }^{6,7}$ Thus the retention of eugenol in the stomach will give betterresults against peptic ulcer by maintaining the effective drug concentration. Eugenol was chosen for this work due to its less use in ulcer healing. Commonly eugenol is used as analgesic agent in dental treatment. The objective of the present research work involves development and evaluation of floating in situ gelling system of eugenol for treating gastric ulcers.

\section{MATERIALS AND METHODS}

\section{Materials}

Eugenol was gifted by Altaroma chemicals Pvt, Ltd (Mumbai) and gellan gum (Gelrite) was giftedfrom CP Kelcocompany (Mumbai). All other materials and chemicals used were of either pharmaceutical or analytical grade.

\section{Animals}

Male wistar rats of 200-280 g were used for the study. All the experimental procedures used in this study were reviewed and followed by Institutional Animal Ethics Committee of STES's Sinhgad College of Pharmacy, Pune, constituted under Committee for Purpose of Control and Supervision of Experiments on Animals. (Approval number is SCOP/IAEC/2014-15/197 dated 05/05/2015.).

\section{Preparation of emulsion}

The accurate quantity of drug and Tween 80 were taken in mortar and water was added slowly drop by drop with continuous stirring until the homogenous emulsion was formed.

\section{Preparation of floating in situ gelling system}

The solutions containing various concentrations of sodium alginate $(0.5-2 \% \mathrm{w} / \mathrm{v})$ were prepared in deionised water containing $0.25 \% \mathrm{w} / \mathrm{v}$ of sodium citrate. This solution was heated up to $70^{\circ} \mathrm{C}$ with stirring and allowed to cool below $40^{\circ} \mathrm{C}$. After cooling, various concentrations of calcium carbonate, HPMC K 100 and drug emulsion were added in respective batches with continuous stirring to form homogeneous dispersion. ${ }^{8}$ The above procedure was repeated for various concentrations of gellan gum $(0.5 \%-2 \% \mathrm{w} / \mathrm{v})$. Table 1 shows compositions of floating in situ gel.

\section{Preliminary screening of calcium carbonate concentration}

The preliminary screening study was carried out for the selection of calcium carbonate concentration in the floating in situ gel formulation. For selection of working concentration range of calcium carbonate the floating in situ gelling systems were prepared using different concentration of calcium carbonate (Table 2). Prepared floating in situ gelling systems were evaluated for gelling capacity, floating study, drug content and for in vitro dissolution study.

\section{Preliminary screening of mannitol concentration}

The preliminary screening study was carried out for the selection of mannitol concentration. The floating in situ gelling systems were prepared using different concentration of mannitol (Table 3). Prepared floating in situ gelling systems were evaluated for gelling capacity, floating study, drug content and for in vitro dissolution study.

\section{EVALUATION PARAMETERS OF FLOATING IN SITU GELLING SYSTEM}

\section{Gelling capacity}

The gelling capacity for the batches was examined visually. The $5 \mathrm{ml}$ of formulation was added in $500 \mathrm{ml}$ of $0.1 \mathrm{~N} \mathrm{HCl}$ containing $5 \%$ sodium lauryl sulphate. The gelling capacity was graded in to three categories on the basis of gelation time and time period for which gel remains intact.

$(+)$ Gels after few minutes, dispersed rapidly, $(++)$ immediate gelation and remains for less than $12 \mathrm{~h}$, $(+++)$ immediate gelation and remains for more than 12 h. ${ }^{.10}$

\section{In vitro floating study}

The floating lag time was determined by measuring the time required for in situ formulation to come atthe surface and show floating behaviour. Total floating time is the total time for which the gel floats in dissolution medium including floating lag time. The floating study was carried out in $0.1 \mathrm{~N} \mathrm{HCl}$ containing $5 \%$ sodium lauryl sulphate by placing $5 \mathrm{ml}$ of formulation. ${ }^{11}$

\section{Drug content}

$5 \mathrm{ml}$ of in situ gel (equivalent to $810 \mathrm{mg}$ of drug) was added to $100 \mathrm{ml}$ of $0.1 \mathrm{~N} \mathrm{HCl}$ containing $5 \%$ sodium lauryl sulphate. The solution was stirred for 1 hour on magnetic stirrer and then solution was filtered and diluted with $0.1 \mathrm{~N} \mathrm{HCl}$ containing $5 \%$ sodium lauryl sulphate. The drug concentration was analysed at $280 \mathrm{~nm}$ by using UV spectrophotometer. ${ }^{12}$ 


\begin{tabular}{|c|c|c|c|c|c|c|c|c|}
\hline Ingredients & F1 & F2 & F3 & F4 & F5 & F6 & F7 & F8 \\
\hline Eugenol $(810 \mathrm{mg} / 5 \mathrm{ml})$ & 8100 & 8100 & 8100 & 8100 & 8100 & 8100 & 8100 & 8100 \\
\hline Tween (80) (ml) & 4 & 4 & 4 & 4 & 4 & 4 & 4 & 4 \\
\hline Sodium alginate (gm) & 0.5 & 1 & 1.5 & 2 & - & - & - & - \\
\hline HPMC K 100 (gm) & 0.5 & 0.5 & 0.5 & 0.5 & - & - & - & - \\
\hline Gellan gum (gm) & - & - & - & - & 0.5 & 1 & 1.5 & 2 \\
\hline Sodium citrate (gm) & 0.25 & 0.25 & 0.25 & 0.25 & 0.25 & 0.25 & 0.25 & 0.25 \\
\hline Calcium carbonate (gm) & 0.5 & 0.5 & 0.5 & 0.5 & 0.5 & 0.5 & 0.5 & 0.5 \\
\hline Water & \multicolumn{8}{|c|}{ q.s up to $50 \mathrm{ml}$} \\
\hline
\end{tabular}

\begin{tabular}{|c|c|c|c|c|}
\hline Ingredients & F9 & F10 & F11 & F12 \\
\hline Eugenol $(810 \mathrm{mg} / 5 \mathrm{ml})$ & 8100 & 8100 & 8100 & 8100 \\
\hline Tween 80 (ml) & 4 & 4 & 4 & 4 \\
\hline Sodium alginate (gm) & 1 & 1 & - & - \\
\hline HPMC K 100 (gm) & 0.5 & 0.5 & - & - \\
\hline Gellan gum (gm) & - & - & 0.5 & 0.5 \\
\hline Sodium citrate (gm) & 0.25 & 0.25 & 0.25 & 0.25 \\
\hline Calcium carbonate (gm) & 1 & 1.5 & 1 & 1.5 \\
\hline Water & \multicolumn{4}{|c|}{ q.s up to $50 \mathrm{ml}$} \\
\hline
\end{tabular}

\begin{tabular}{|c|c|c|c|c|c|c|}
\hline Ingredients & F13 & F14 & F15 & F16 & F17 & F18 \\
\hline Eugenol 810 (mg/5 ml) & 8100 & 8100 & 8100 & 8100 & 8100 & 8100 \\
\hline Tween $80(\mathrm{ml})$ & 4 & 4 & 4 & 4 & 4 & 4 \\
\hline Sodium alginate (gm) & 1 & 1 & 1 & - & - & - \\
\hline HPMC K 100 (gm) & 0.5 & 0.5 & 0.5 & - & - & -- \\
\hline Gellan gum (gm) & - & - & - & 0.5 & 0.5 & 0.5 \\
\hline Sodium citrate (gm) & 0.25 & 0.25 & 0.25 & 0.25 & 0.25 & 0.25 \\
\hline Calcium carbonate (gm) & 1 & 1 & 1 & 1 & 1 & 1 \\
\hline Mannitol (gm) & 0.16 & 0.18 & 0.2 & 0.16 & 0.18 & 0.2 \\
\hline Water & \multicolumn{6}{|c|}{ q.s. up to $50 \mathrm{ml}$} \\
\hline
\end{tabular}

\section{In vitro drug release study}

The in vitro drug release studies of the formulations were performed using USP Type II dissolution apparatus containing $500 \mathrm{ml}$ of $0.1 \mathrm{~N} \mathrm{HCl}$ with $5 \%$ of sodium lauryl sulphate as dissolution media at $50 \mathrm{rpm}$. The temperature was maintained at $37^{\circ} \mathrm{C}$. The $5 \mathrm{ml}$ of formulation containing $810 \mathrm{mg}$ of eugenol was placed in the dissolution media, aliquots of $10 \mathrm{ml}$ were withdrawn at regular interval on hourly basis up to $12 \mathrm{~h}$. The samples were replaced with the fresh medium to maintain sink condition. The aliquots were analysed by using UV spectrophotometer at $280 \mathrm{~nm} .{ }^{8,13}$

\section{Rheological study}

The rheological study of finalised batch was carried out by using Anton Paarrheometer MCR 102. ${ }^{14,15}$

\section{IN VIVO STUDY}

\section{Pylorus ligation method}

The in vivo study was carried out for finalised formulation by pylorus ligation method. Four groups of wistar rats were used. Animals were fasted for $24 \mathrm{~h}$ before pylorus ligation but allowed free access to water. The rats were 
divided into four groups of six animals. The following groups of animals were used for study.

Group I: Normal control

Group II: Gastric ulcer control

Group III: Standard omeprazole $(20 \mathrm{mg} / \mathrm{kg})$

Group IV: Eugenol floating in situ formulation $(100 \mathrm{mg} / \mathrm{kg})$

Thirty minutes after oral dosing the Wistar rats were anaesthetized with anaesthetic ether and a portion of the abdomen was opened by a small midline incision below the xiphoid process. The pylorus portion of the stomach was lifted and ligated. During this process, care was taken to avoid the traction to the pylorus or damage to its blood supply. The stomach was closed by interrupted sutures. Animals in all the 4 groups after $5 \mathrm{~h}$ of ligation were sacrificed and the stomachs were removed, cut along the greater curvature and observed for ulcer. The numbers of ulcers were counted using a magnifying glass. The following arbitrary scoring system was used to grade the incidence and severity of lesions. The following scoring system was used to grade the incidence and severity of lesions. ${ }^{16,17}$

$0=$ No ulcer

$1=$ Superficial ulcer

$2=$ Deep ulcer

$3=$ Perforation

The ulcer index and percent inhibition of ulceration were determined using following formulae. Ulcer index (UI) was then calculated from the above scorings as follows:

where,

$$
\mathrm{UI}=\mathrm{U}_{\mathrm{N}}+\mathrm{U}_{\mathrm{S}}+\mathrm{U}_{\mathrm{P}} \times 10^{-1}
$$

$U_{\mathrm{N}}$ is the average of number of ulcers per animal,

Us is the mean severity of ulcer score

$U_{p}$ is the percentage of animals with ulcer incidence

Percentage inhibition of ulceration was calculated as follows:

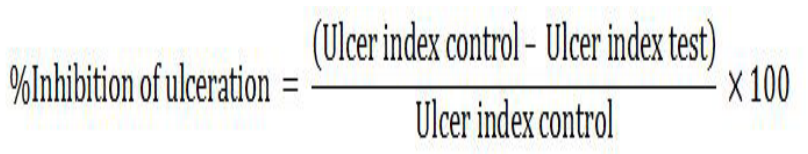

\section{Statistical Analysis}

In vivo experimental results were expressed as mean \pm S.E.M. Data were analysed by analysis of variance (ANOVA) followed by Tukey's multiple comparison test, with the level of significance set at $\mathrm{P}<0.05$. All the in vivo experimental results are expressed as mean \pm S.E.M. of three parallel measurements.

\section{In vivo X- Ray imaging Study}

For ascertaining the floating behaviour; X-Ray is the main evaluation parameter for floating dosage form. The animals were fasted overnight with free access to water, and radiography was made after the oral administration of formulation. The radio-opaque material barium sulphate was used for visualization of dosage form by $\mathrm{X}-$ Ray. The gastric radiography was done after the $1 \mathrm{~h}$ and $12 \mathrm{~h}$ of oral administration of formulation. ${ }^{18}$ The study was approved by the institutional Animal Ethical committee.

\section{RESULTS}

\section{Gelling capacity and floating study}

The gelling capacity and floating study were carried out in $500 \mathrm{ml}$ of $0.1 \mathrm{~N} \mathrm{HCl}$ containing $5 \%$ sodium lauryl sulphate.

Preliminary screening of calcium carbonate concentration

\section{In vitro drug release study}

Preliminary screening of mannitol concentration.

\section{IN VIVO STUDY}

\section{Pylorus ligation method}

In vivo study was performed for checking the effect of eugenol for ulcer treatment by pylorus ligation method. Parameters estimated were ulcer index and \% inhibition of ulceration. Results of group II showed ulcer while results of group III and IV showed reduction in ulceration after $5 \mathrm{~h}$ of the treatment, the values of ulcer index and \% inhibition are given in Table 7.

\section{In vivo X-ray imaging study}

The in vivo floating behaviour of formulation with barium sulphate was carried out in rats by X-Ray imaging. X-ray was taken after oral administration of gelling formulation at the end of $1 \mathrm{~h}$ and at $12 \mathrm{~h}$.

\section{DISCUSSION}

The two main pre-requisites of the floating in situ gelling systems include free flowing liquid easy for swallowing and instant gelation in acidic environment. The mechanism of gelation involves the formation of double helical junction zones followed by aggregation of double helical segments to form a three-dimensional network by complexing with cations and hydrogen bonding with water. ${ }^{8}$. The sol to gel transformation of gellan and sodium alginate occurs in the presence of either monovalent or divalent cations in contacts with the gastricfluids. 
Table 4: Evaluation of floating in situ gelling system containing sodium alginate and gellan

\begin{tabular}{|c|c|c|c|c|c|c|}
\hline Batches & $\begin{array}{c}\text { Sodium alginate } \\
(\% \mathbf{w} / \mathbf{v})\end{array}$ & $\begin{array}{c}\text { Gellan gum } \\
(\% \mathbf{w} / \mathbf{v})\end{array}$ & Pourability & $\begin{array}{c}\text { Gelling } \\
\text { capacity }\end{array}$ & $\begin{array}{c}\text { Floating lag } \\
\text { time }\end{array}$ & $\begin{array}{c}\text { Total floating } \\
\text { time(h) }\end{array}$ \\
\hline F1 & 0.5 & - & Easy to Poured & + & & \\
\hline F2 & 1 & - & Easy to poured & ++ & $<5$ & $<12$ \\
\hline F3 & 1.5 & - & Pourable & +++ & $<5$ & $>12$ \\
\hline F4 & 2 & - & Difficult to poured & +++ & $<5$ & $>12$ \\
\hline F5 & - & 0.5 & Easy to poured & ++ & $<5$ & $<12$ \\
\hline F6 & - & 1 & Pourable & ++ & $<5$ & $<12$ \\
\hline F7 & - & 1.5 & Difficult to poured & +++ & $<5$ & $>12$ \\
\hline F8 & - & 2 & Difficult to poured & +++ & $<5$ & $>12$ \\
\hline
\end{tabular}

\begin{tabular}{|c|c|c|c|c|c|}
\hline Batches & Pourability & $\begin{array}{c}\text { Gelling } \\
\text { capacity }\end{array}$ & Floating lag time & Total floating time & Drug content \\
\hline F9 & Easy to Poured & ++ & $<1 \min$ & $<12 \mathrm{~h}$ & $93.74 \%$ \\
\hline F10 & Pourable & +++ & $<1 \min$ & $>12 \mathrm{~h}$ & $94.42 \%$ \\
\hline $\mathrm{F} 11$ & Easy to Poured & ++ & $<1 \min$ & $<12 \mathrm{~h}$ & $97.34 \%$ \\
\hline $\mathrm{F} 12$ & Difficult to poured & +++ & $<1 \min$ & $>12 \mathrm{~h}$ & $98.17 \%$ \\
\hline
\end{tabular}

\begin{tabular}{|c|c|c|c|c|c|c|c|}
\multicolumn{6}{|c|}{ Table 6: Evaluation of floating in situ gelling system using different concentration of mannitol } \\
\hline Batches & $\begin{array}{c}\text { Sodium } \\
\text { alginate \%w/v }\end{array}$ & $\begin{array}{c}\text { Gellan gum } \\
\% w / v\end{array}$ & $\begin{array}{c}\text { Mannitol } \\
\% \text { w/v }\end{array}$ & Gel capacity & $\begin{array}{c}\text { Floating } \\
\text { lag time }\end{array}$ & $\begin{array}{c}\text { Total Floating } \\
\text { time }\end{array}$ & Drug content \\
F13 & 1 & - & 0.16 & ++ & $<1 \mathrm{~min}$ & $>12 \mathrm{~h}$ & $94.56 \%$ \\
F14 & 1 & - & 0.2 & + & $<1 \mathrm{~min}$ & $<3 \mathrm{~h}$ & $95.67 \%$ \\
F15 & 1 & - & 0.24 & + & $<1 \mathrm{~min}$ & $<1 \mathrm{~h}$ & $95.98 \%$ \\
F16 & - & 0.5 & 0.16 & ++ & $<1 \mathrm{~min}$ & $>12 \mathrm{~h}$ & $97.26 \%$ \\
F17 & - & 0.5 & 0.2 & + & $<1 \mathrm{~min}$ & $<3 \mathrm{~h}$ & $96.48 \%$ \\
F18 & - & 0.5 & 0.24 & + & $<1 \mathrm{~min}$ & $<1 \mathrm{~h}$ & $96.78 \%$ \\
\hline
\end{tabular}

\section{Table 7: Effect of treatment on pylorus ligation induced gastric ulcer in rats}

\begin{tabular}{|c|c|c|c|}
\hline Treatment & Dose (mg/kg) & Ulcer index & $\%$ inhibition of ulceration \\
\hline Ulcer control & - & $10.5 \pm 0.2^{* * *}$ & $\cdots$ \\
\hline Standard omeprazole & 20 (p.o) & $4.4 \pm 1.2^{* * *}$ & $62.23 \pm 0.63 \%$ \\
\hline Formulation (Eugenol) & $28($ p.o) & $3.6 \pm 0.16^{* * *}$ & $70.06 \pm 0.81 \%$ \\
\hline
\end{tabular}

Values are represented as mean \pm S.E.M.; $n=6$ in each group. $\left({ }^{* * *} P<0.001\right)$ for ulcer control) (One-way ANOVA followed by Tukey's Multiple Comparison test).

The calcium carbonate present in the formulation as insoluble dispersion dissolves on reaction with acid and releases carbon dioxide. The in situ released calcium ions results in formation of gel. The released carbon dioxide is entrapped in the gel network of the formulation and the gel rises to the surface of the dissolution medium (in-vitro) or the stomach (in-vivo). ${ }^{14}$

\section{Gelling capacity and floating study}

The gelling capacity and floating study were carried out in $500 \mathrm{ml}$ of $0.1 \mathrm{~N} \mathrm{HCl}$ containing $5 \%$ sodium lauryl sulphate. Results of gelling capacity and floating parameters are shown in Table 4. The batches F1-F8 prepared for the selection of polymer concentration. Batches F1-F4 contains various concentrations of sodium alginate 
and batches F4-F8 contained gellan gum in various concentrations. It was observed that as the concentrations of polymer increases the viscous nature of the formulation increases and they become more difficult to pour. The batch F1 did not show formation of gel; it may be due to low concentrations of polymer. The F2, F3, F5 and F6 batches showed gelation immediately that remained for less than 12 h. F4, F7 and F8 batches showed immediate gelation which remained undisturbed for more than $12 \mathrm{~h}$ (Table 4). F2-F8 batches shows floating lag time $5 \mathrm{~min}$ and total floating time up to $12 \mathrm{~h}$. The F1, F3, F4, F6, F7 and F8 batches were rejected because they were more viscous in nature as compared to batches F2 and F5. Thus F2 and F5 containing $1 \% \mathrm{w} / \mathrm{v}$ and $0.5 \% \mathrm{w} / \mathrm{v}$ of their respective polymers concentrations were used further for the selection of calcium carbonate concentration.

\section{Preliminary screening of calcium carbonate concentration}

The calcium carbonate plays important role in the formation of gel as well as it helps gel to float. The formulation with low amount of calcium carbonate forms weak gels and shows more time to float. Such vehicles are not suitable for oral liquid formulations because they will be removed earlier from the stomach by the peristaltic movements. ${ }^{19}$

The batches F9-F12 were prepared for the screening of working concentrations of calcium carbonate (Table 2), the results of these batches are shown in Table 6. As concentration of calcium carbonate increases, floating lag time decreases and total floating time increases. The floating of gel depends mainly on the calcium carbonate and polymer concentration. It was also observed that with increase in amount of calcium carbonate the viscous nature of all the formulation increases. It occurred because the calcium carbonate is present in insoluble dispersion, as concentrations of calcium carbonate increases the number of dispersed particles in the formulation increases and formulations become viscous and are difficult to pour. ${ }^{8,14,19}$ The batches F10 and F12 were found to be more viscous than batch F9 and F11. The 1\% concentration of calcium carbonate was selected, as it shows good gelling as well as floating properties (Table 5).

\section{Drug content}

All batches showed drug content in the range of 93.74$98.17 \%$. Batch F10 and F12 shows high drug content but unacceptable pourability, Hence batches F10 and F12 were rejected. F9 and F11 batches were selected for in vitro dissolution study because of their high drug content and good pourability (Table 5).

\section{In vitro drug release study}

The formulations F9 and F11 were subjected to in vitro drug dissolution studies. Dissolution was performed in $0.1 \mathrm{~N} \mathrm{HCl}$ containing 5\% sodium lauryl sulphate. F9 batch showed $51.32 \%$ of drug release after $12 \mathrm{~h}$ while F11 batch showed $57.2 \%$ of drug release as shown in Figure 1. Thus, there was need to add channel opening agent in the formulation. The batches F13-F18 were prepared for selection of concentration of channel opening agent as shown in Table 3.

\section{Preliminary screening of mannitol concentration}

Mannitol is used in the formulation as channel forming agent. ${ }^{20}$ Batches F13-F16 were prepared for selection of working concentration range of mannitol (Table 3). The working concentration range of mannitol was determined on the basis of gelling capacity, floating properties, drug content and mainly on in vitro drug released study. The mannitol in low concentrations is more effective than the high concentration. As concentration of mannitol increases the gelling capacity of the formulations decreases and gel disappears within 1-3 h. In the minimum concentration it forms channels in to the polymer matrix and maintains gelling capacity as well as floating properties of the formulation. Thus mannitol in $0.16 \% \mathrm{w} / \mathrm{v}$ was found to be effective for floating in situ gelling system (Table 6). The batch F13 and F16 shows good gelling capacity $(++)$, total floating time up to $12 \mathrm{~h}$ and floating lag time was less than $1 \mathrm{~min}$. All batches of mannitol showed drug content in the range of $94.56 \%-97.27 \%$. The batches F14, F15, F17 and F18 were rejected because they showed poor gelling capacity and disperse within 1-3 h. Rapid dispersion of gel could be because of high percentage of mannitol which creates pore in the matrix.

The batches F13 and F16 were selected for the further in vitro dissolution studies. The increase in the drug release observed may be due to presence of mannitol, as this agent forms pores in the gel matrix and helps drug to come out from the polymer matrix and shows increased in drug release. The sodium alginate batch F13 was found to sustain drug release for more time than the gellan gum batch F16. However, F16 batch showed high drug content than the F13 batch (Table 6). Thus F16 was finalized for further studies depending upon gelling capacity, floating properties, drug content $(97 \%)$ and in vitro drug release $(94.78 \%$ ) (Figure 2).

\section{Rheological study}

The graph of storage modulus versus time and loss modulus versus time were plotted using Anton Paarrheometer (Figure 3). The graph indicates that there 


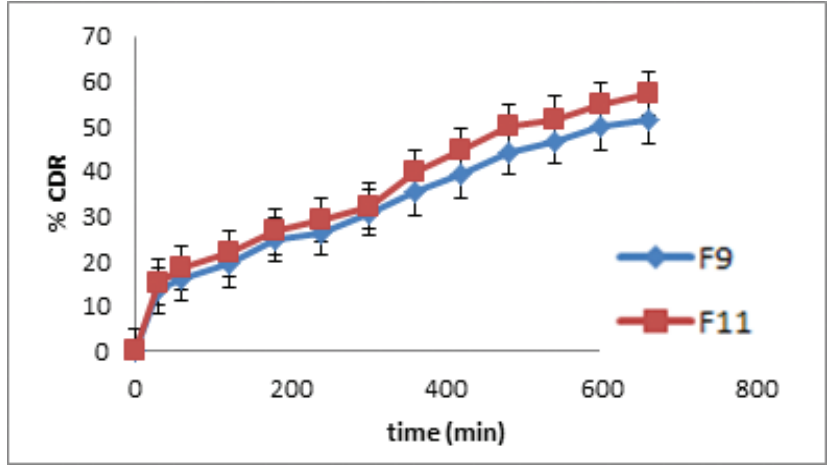

Figure 1: Dissolution profile of batches in $0.1 \mathrm{~N} \mathrm{HCl}$ with $5 \%$ of sodium lauryl sulphate.

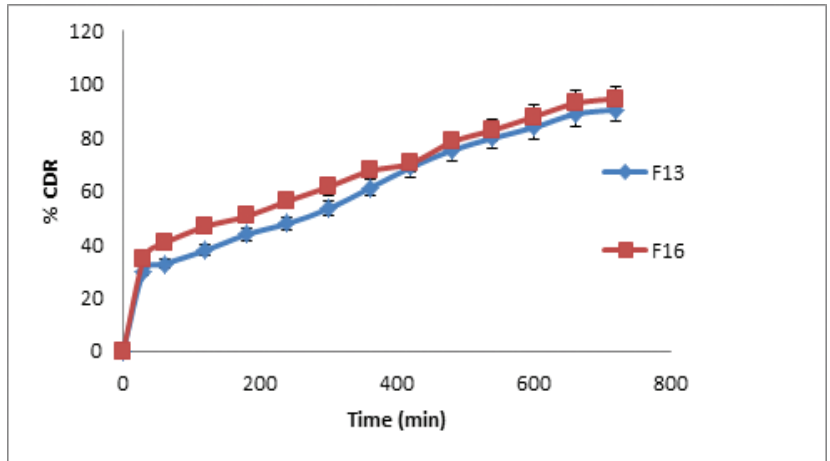

Figure 2: Dissolution profile of batches in $0.1 \mathrm{~N} \mathrm{HCl}$ with $5 \%$ sodium lauryl sulphate Rheological study.

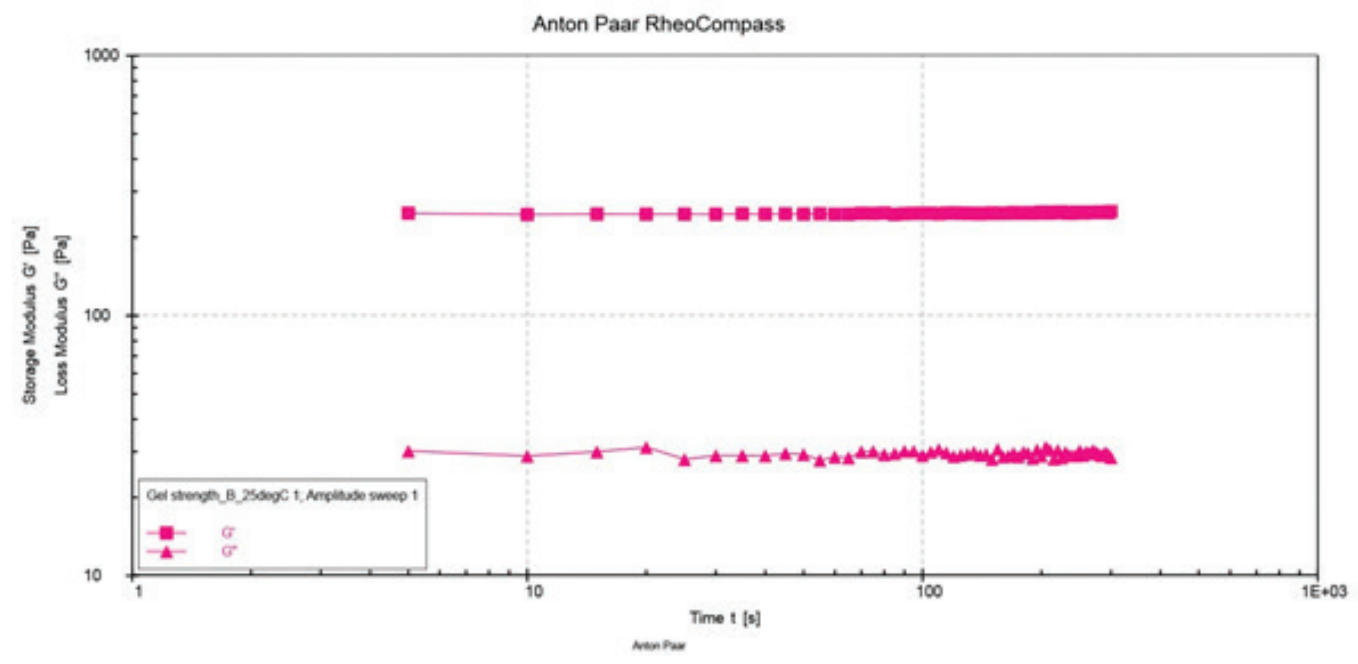

Figure 3: Storage modulus vs time $\mathrm{G}^{\prime}\left({ }^{-}\right)$, loss modulus vs time $\mathrm{G}^{\prime \prime}\left({ }^{\star}\right)$.

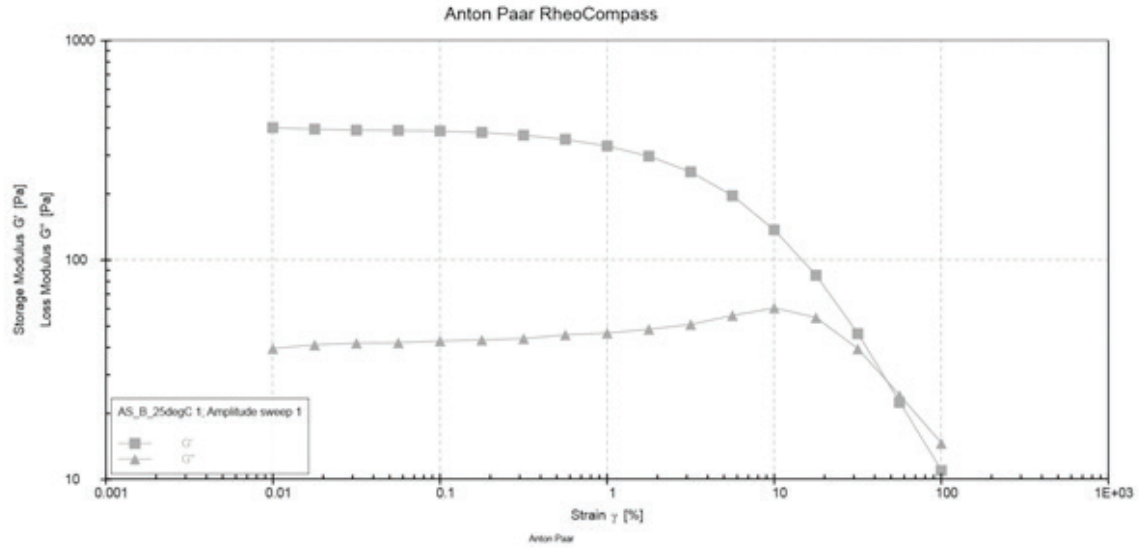

Figure 4: Storage modulus vs strainG' ( $\left.{ }^{-}\right)$, loss modulus vs strain $G^{\prime \prime}\left(\AA^{-}\right)$. 


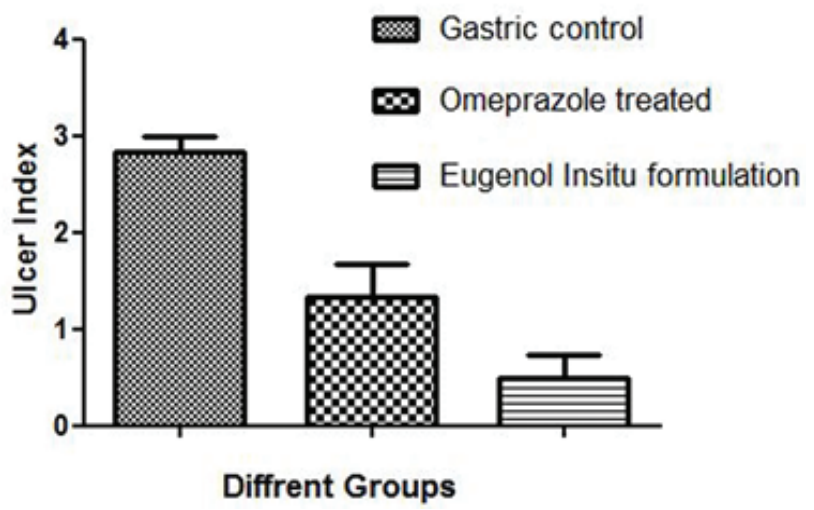

Figure 5: Graph of ulcer index in different groups.
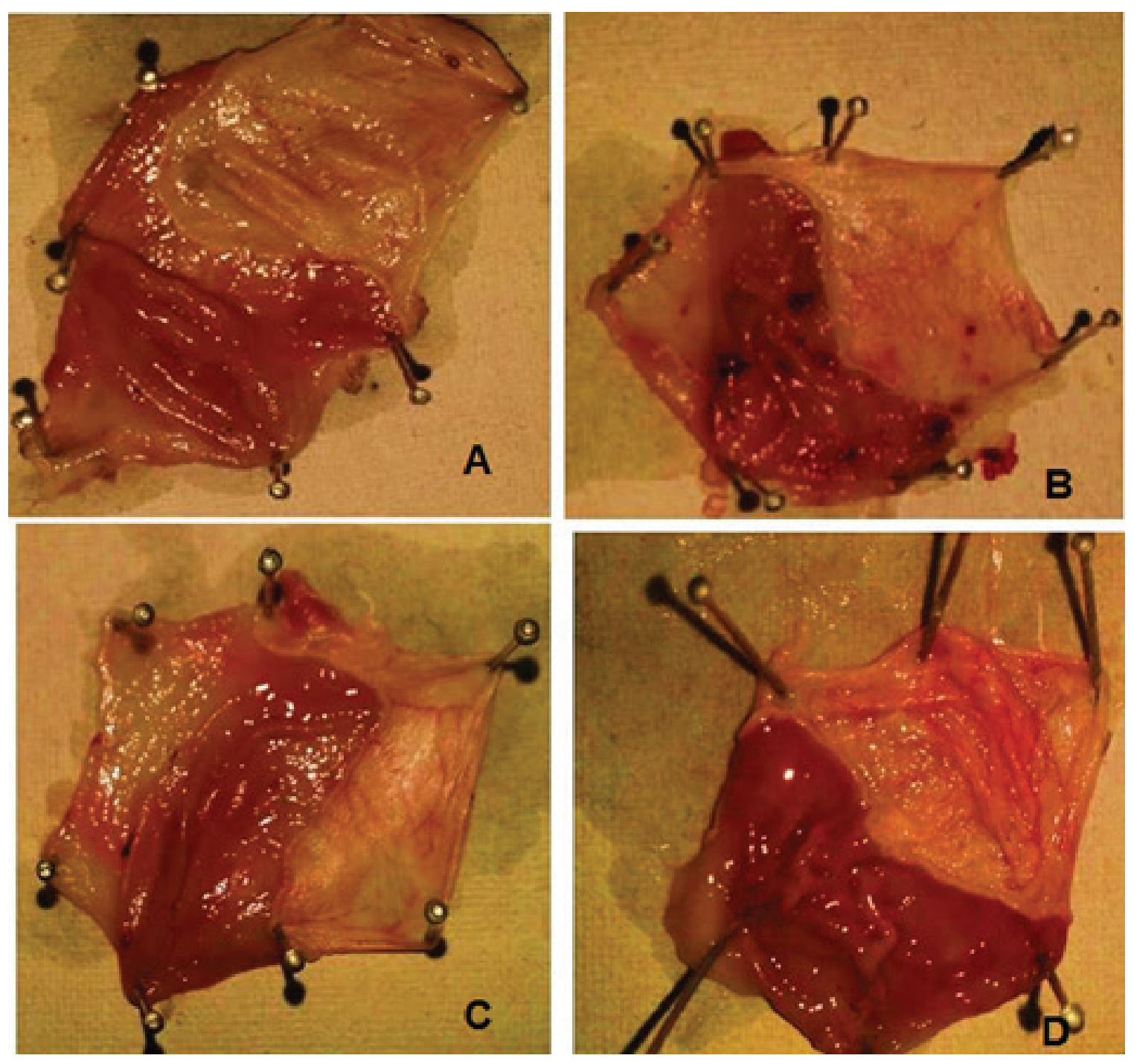

Figure 7: Photographs of rat stomach showing ulcerated area A. Normal control, B. Ulcer control, C. Treated with standard omeprazole, D. Treated with optimized formulation. 

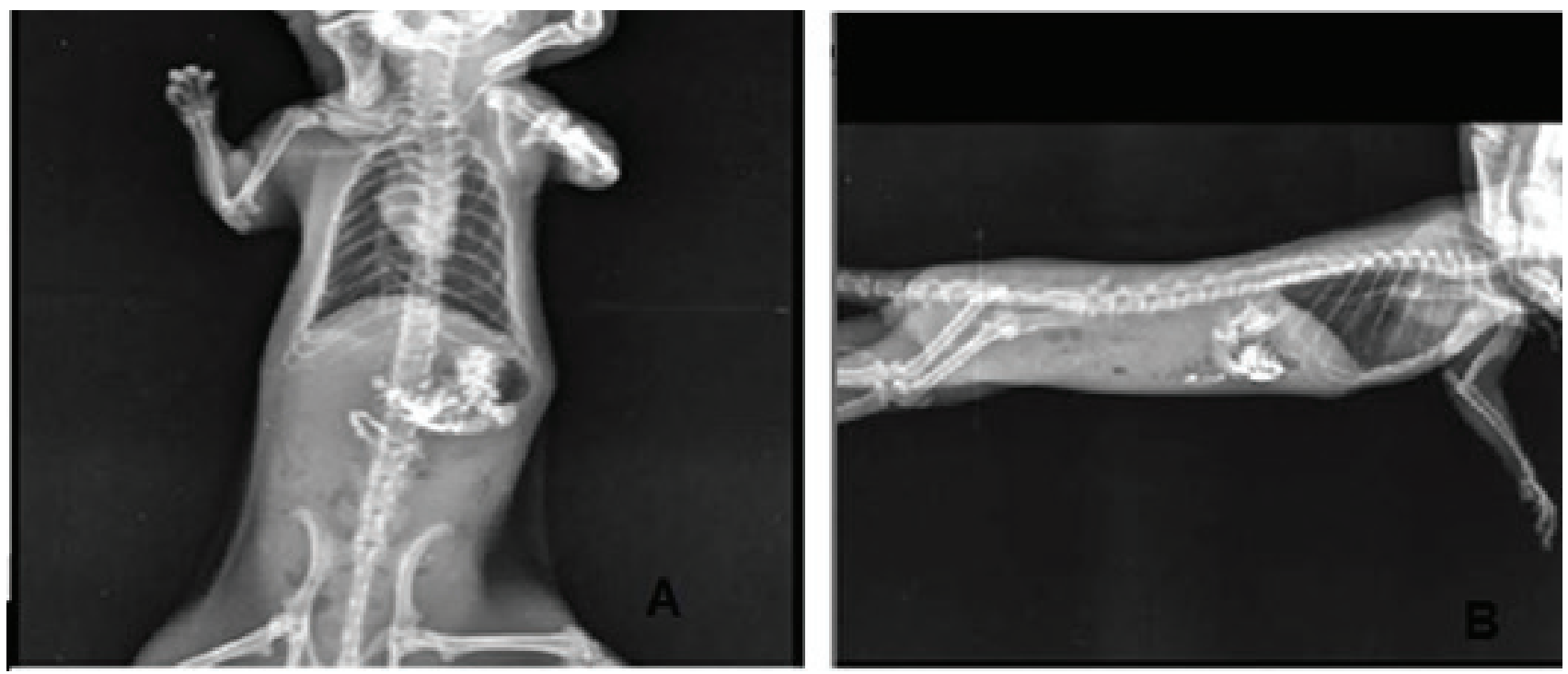

Figure 8: X- Ray photographs showing floating ability of gel (A) at $1 \mathrm{~h}(B)$ at $12 \mathrm{~h}$.

is no change in storage modulus and loss modulus of formulation. This justifies stability of formulation with respect to rheological changes with time; the studies were carried out for $300 \mathrm{sec}$. at temperature $25^{\circ} \mathrm{C}$.

The graph was also plotted to understand the rheological characteristic of formulation. The decrease in storage modulus was observed with increase in strain (Figure 4). The formulation was stable as strain increases from $0-10 \%$. Further increase in strain decreases storage modulus of the formulation it becomes 0 at $100 \%$ strain. This indicates that the formulation in solution state is shear thinning system. Thus it can be concluded that formulation is stable at $10 \%$ strain.

\section{IN VIVO STUDY}

\section{Pylorus ligation method}

The ulcer index of group II was found to be $10.5 \pm 0.2^{* * *}$ (Figure 7B). In case of group III ulcer index was $4.4 \pm$ $1.2^{* * *}$ (Figure 7C), while in group IV the ulcer index was found to be $3.6 \pm 0.16^{* * *}$ (Figure 7D). The $\%$ inhibitions of ulcer in group III and IV were found to be $62.23 \pm$ $0.63 \%$ and $70.06 \pm 0.81 \%$ respectively (Figure 5,6 ). The in situ formulation of eugenol shows $70 \%$ of ulcer inhibition. Eugenol increases the mucus secretion in gastric region, it acts as antioxidant, prevent the synthesis of lipid peroxidation and decreases nitric oxide level in the GI region. Eugenol exhibits its activity due to presence of phenolic group. Thus, it was concluded that eugenol floating in situ gel formulation has the gastro protective activity and can be used in treatment of gastric ulcer.

\section{In vivo X-ray imaging study}

From the Figure 8, image-A was taken at the end of 1 hour after the administration of gelling solution the gel formation was seen. Image B was taken at the end $12 \mathrm{hr}$. The photographs revealed that there was formation of gel and floating of gel observed (Figure 8). The opacity was seen due to release of barium sulphate.

\section{CONCLUSION}

The prepared floating in situ gelling system has feasibility of forming gel in stomach and sustaining the drug release from the over the period of $12 \mathrm{~h}$. Its ease of administration with reduced frequency of administration results in better patient acceptance. In vivo studies confirmed antiulcer effect of formulation and suggests its usage in treatment of gastric ulcer.

\section{ACKNOWLEDGEMENT}

The authors are grateful to Altaroma Chemicals Mumbai for providing the gift sample of eugenol. Anton Paar, Mumbai is also thanked for their valuable contribution in rheological studies.

\section{CONFLICTS OF INTEREST}

The author have no conflict of interest to declare.

\section{ABBREVIATION USED}

HCl: Hydrochloric acid

HPMC: Hydroxy propyl methyl cellulose. 


\section{REFERENCES}

1. Pankaj D, Praveen S, Dinesh KJ. Systematic evaluation of antiulcer activity of herbal formulation 'chandanasava' in rats. Asian pacific Journal of Tropical Disease. 2012;s192-6.

2. Dilpreet K, Ranna AC, Sharma N. Herbal drugs with anti-ulcer activity. Journal of Applied Pharmaceutical Science. 2012;02-(03):160-5.

3. Francesca B, Angelo Al. The Plant Kingdom as a Source of Anti-ulcer Remedies. Phytotherapy Research phytother. Res. 2000;14(8):581-91.

4. Capassoa R, Pintob L, Vuottoc G, Carlo D. Preventive effect of eugenol on PAF and ethanol-induced gastric mucosal damage. 2000;Fitoterapia 71. http://dx.doi.org/10.1016/s0367-326x(00)00188-x.

5. Mohamed A, Morsy A, Fouad A. Mechanisms of gastroprotective effect of eugenol in indomethacin-induced ulcer in rats. Phytother Res. 2008;22(10):1361-6. http://dx.doi.org/10.1002/ptr.2502; PMid:18543354.

6. Joohee J, Hyuk LK, Hwan B. Anti-gastric actions of eugenol andcinnamic acid isolated from cinnamon ramulus. Yakugaku Zasshi. 2011;13(7):1103-10.

7. José RS, Marivane L, Luiz CK-Jr. Gastroprotective activity of essential oil of the Syzygiumsaromaticumand its major component eugenol in different animal models. Naunyn-Schmied Arch Pharmacol. 2011;383(2):149-58. http://dx.doi.org/10.1007/s00210-010-0582-x; PMid:21140134.

8. Rajinikanth PS, Mishra B, Balasubramaniam. Floating in situ gelling system of acetohydroxamic acid for clearance of $\mathrm{H}$. Pylori. Drug Development and Industrial Pharmacy. 2008;34(6):577-87. http://dx.doi. org/10.1080/03639040701831819; PMid:18568907.

9. Neema GP, Ramchandra VK. Formulation and Development of Alfuzosin Hydrochloride Buoyant in situ gel. American Journal of Pharmatech Research. 2013;3(4):760-83.

10. Rajalakshmi R, Diwakar NR. Development and evaluation of a novel floating in-situ gelling system of azithromycin Dihydrate. Indo American Journal of Pharmaceutical Research. 2013;3(4):3821-31.
11. Dasharath MP, Divyesh KP, Chhagan NP. Formulation and Evaluation of Floating Oral In situ Gelling System of Amoxicillin. ISRN Pharmaceutics Article. 2011;ID 276250.

12. Mahagen $\mathrm{Y}$, Patidhar V, Balaram Y, Gopkumar P, Sridevi G.Formulation and evaluation of floatable in-situ gel for stomach-specific drug delivery of carbamazepine. Journal of pharmacy and pharmaceutical Sciences. 2013;2320-1215.

13. Pandya K, Agrawal P, Dashora A. Formulation and evaluation of oral floatable in-situ gel of ranitidine hydrochloride. Journal of Drug Delivery and Therapeutics. 2013;3(3):90-7.

14. Mishra B, Rajinikanth PS, Balasubramaniam J. Development and evaluation of a novel floating in situ gelling system of amoxicillin for eradication of Helicobacter pylori. International Journal of Pharmaceutics. 2007;335(1):114-22. PMid:17141986.

15. Miyazaki S, Kubo W. Oral sustained delivery of paracetamol from in situ gelling gellan and sodium alginate formulations. International Journal of Pharmaceutics. 2003;258(1):55-64. PMid:12753753.

16. Gerhard HV. Wolfgang HV, Bernward AS, Jurgen S. Drug discovery and evaluation. pharmacological assays, $2^{\text {nd }}$ edition, springer. 2012. p.867.

17. Ranade AN, Wankhede S, Ranpise N, Mundada MS. Development of bilayer floating tablet of amoxicillin and aloe vera gel powder for treatment of gastric ulcers. AAPS Pharm Sci Tech. 2012;13(4):1518-23. http://dx.doi.org/10.1208/ s12249-012-9882-4 ; PMid:23135966 PMCid:PMC3513446.

18. Swathi G, Lakshmi PK. Design and Optimization of Hydrodynamically Balanced Oral In situ Gel of Glipizide. Journal of Applied Pharmaceutical Science. May. 2015;5(Suppl1): 31-8.

19. Mishra B, Rajinikanth PS. Floating in situ gelling system for stomach sitespecific delivery of clarithromycin to eradicate Helicobacter pylori. Journal of Controlled Release. s2008;125(1):33-41.

20. Rowe RC, Sheskey PJ, Weller PJ. Handbook of Pharmaceutical Excipients. $5^{\text {th }}$ ed. London: Pharmaceutical press. 2006:449-52.

\section{SUMMARY}

- The objective of this study was to develop a novel in-situ gel system of eugenol for treatment of peptic ulcer.

- Protective effect of eugenol against ulcer is documented but less practiced.

- The delivery system consists of varying concentrations of sodium alginate, gellan gum and calcium carbonate.

- The prepared floating in situ gelling system has feasibility of forming gel in stomach and sustaining the drug release from the over the period of $12 \mathrm{~h}$.

- Its ease of administration with reduced frequency of administration results in better patient acceptance. 